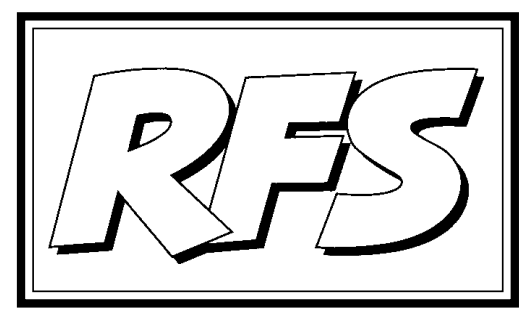

Revista de Fomento Social, 58 (2003), 187-190

\title{
La guerra es una derrota de la humanidad
}

Fernando F. FRANCO, S. J.*

Mis queridos compañeros en el Señor:

En su discurso al cuerpo diplomático, J uan Pablo II proclamó enfáticamente que la "guerra nunca es una simple fatalidad, es siempre una derrota de la humanidad"1. Estas palabras Ilenas de angustia del Papa reflejan la creciente preocupación de la Santa Sede por los efectos que la violencia y la guerra tienen sobre el frágil tejido de la coexistencia humana. En su mensaje a la Organización de las Naciones Unidas en octubre de 1965, Pablo VI habló del solemne compromiso que todos tenemos que contraer: “iNunca jamás guerra! ¡Nunca jamás guerra!"2. Con ocasión de la guerra del Golfo Pérsico, Juan Pablo ll expresó los mismos sentimientos con un grito parecido: “iNunca más la guerra!"3. Encomiando los esfuerzos de quienes trabajan por la paz, el

* Secretario del Secretariado para la Justicia Social de la Compañía de Jesús.

1 Discurso del Santo Padre al Cuerpo Diplomático acreditado ante la Santa Sede, 13 enero 2003.

2 Mensaje de Paz a las Naciones Unidas, 4 de octubre de 1965.

3 Centesimus annus, 52. 
mismo Papa considera como un nuevo signo de esperanza "el incremento, en muchos estratos de la opinión pública, de una nueva sensibilidad cada vez más contraria a la guerra como instrumento de solución de los conflictos entre los pueblos"4.

Como respuesta a la trágica violencia del 11 de setiembre, la Conferencia Episcopal de los Estados Unidos, difundió el 13 de noviembre de 2002 un Comunicado sobre Irak, donde decía claramente que "sobre la base de los hechos que nosotros conocemos, seguimos creyendo que es difícil justificar el recurso a la guerra contra Irak, por no tener una clara y adecuada evidencia de un ataque inminente de naturaleza grave". En el mismo espíritu, y en carta dirigida al Presidente Bush el 19 de octubre de 2002, los provinciales jesuitas de Estados Unidos expresaron categóricamente "fuertes reservas de carácter moral sobre el uso de la fuerza en Irak". A estas voces se unen los testimonios de muchos jesuitas de todo el mundo que, en circunstancias muy difíciles, difunden el mensaje del diálogo y de la paz en medio de la violencia, así como la preocupación de otros muchos que han instado al Secretariado para la Justicia Social a que apoye estos esfuerzos por la paz.

Fieles a nuestro compromiso de ser "servidores de la misión de Cristo"5, y en esta coyuntura crítica, nuestra determinación de trabajar por una paz anclada firmemente en la justicia debe encauzarse a través de una madura reflexión en espíritu de oración sobre las razones principales que se oponen a una guerra contra Irak. Creemos, con muchos otros, que las razones de un ataque preventivo contra Irak no son convincentes, y que los efectos de una posible guerra contra Irak serían tan devastadores que sería muy difícil, si no del todo imposible, justificar una intervención militar. Nuestra opinión se basa en las consideraciones siguientes:

1) La "doctrina" de la guerra preventiva no está de acuerdo con la doctrina y el derecho de la $\mathrm{ONU}^{6}$, ni es moralmente sostenible ${ }^{7}$. La aplicación de esta doctrina abriría las puertas a una guerra infinita, a "una guerra sin fin".

2) En lugar de traer una paz duradera a la región (Medio Oriente), una

4 Evangelium vitae, 27.

5 Congregación General 34, Decreto 1, no. 1.

6 Ver Carta de las Naciones Unidas, Artículos 39 y 42.

7 Catecismo de la Iglesia Católica, 2309. 
guerra contra Irak aumentaría las tensiones entre musulmanes y cristianos. Las semillas del diálogo entre ambos grupos, tan pacientemente sembradas, serían aplastadas por una espiral de violencia e intolerancia.

3) La determinación de incurrir en masivos gastos militares, que destruyen la vida, está en marcado contraste con la falta de interés por promover, con igual decisión, el desarrollo sostenible para todos. En un mundo donde las desigualdades aumentan, donde la mayoría no puede satisfacer sus necesidades básicas, donde el comercio y las finanzas benefician a los países ricos más que a los pobres, muchos continúan preguntándose con creciente inquietud si los verdaderos motivos de la guerra contra Irak no tendrán más que ver con móviles económicos que con razones de seguridad.

4) En el nuevo orden político global que está naciendo, los líderes de unos pocos países industrializados se han propuesto tomar unilateralmente decisiones que afectan a la vida de los pueblos de todos los continentes, al margen del control de la ONU y sin atender a su obligación de construir un consenso más amplio a través de legítimos procesos democráticos.

5) La experiencia nos ha enseñado que los pobres son siemprelas víctimas principales de la violencia y de la guerra. Como jesuitas, somos "amigos del Señor", y esto significa "ser 'amigos de los pobres' [y que no] podemos volvernos de lado cuando nuestros amigos están en necesidad"8. En una situación de violencia generalizada y cuando una guerra se proyecta como inevitable, no podemos apartar nuestra mirada de aquellos que profesamos como amigos, los pobres, especialmente las mujeres y los niños. Desde su perspectiva no se puede justificar la guerra.

Estas son las razones por las cuales nuestros esfuerzos a favor de la paz adquieren una apremiante urgencia. Mientras sea posible, y teniendo en cuenta las condiciones locales, nuestra lucha en contra de la constante violencia y a favor de la paz necesita fortalecerse, hacerse más articulada e integrarse en otras iniciativas tanto nacionales como internacionales. Para alcanzar estos objetivos, los jesuitas del sector de la acción social por la justicia deben contribuir, en el ámbito provincial, a crear los espacios

8 Congregación General 34, Decreto 2, oㅡ 9. 
apropiados para que otros jesuitas y nuestros colaboradores puedan reflexionar de manera creativa, preparar planes de acción pública y discernir caminos concretos de colaboración con otros grupos.

En definitiva, nuestros esfuerzos a largo plazo deben partir del hecho evidente de que, como J uan Pablo II lo ha manifestado repetidamente, "existe un gran desorden en la situación del mundo contemporáneo", y que "todos deben colaborar en la constitución de una nueva organización de toda la familia humana" ${ }^{\prime \prime}$ que pueda ser percibida como garante imparcial y objetiva de los derechos.

Enraizados en nuestra fe en J esucristo, que nos llamó a trabajar en su Reino, nos unimos a tantas hermanas y hermanos que luchan por un mundo de justicia, de verdad y de paz. Un mundo donde la verdadera paz pueda convertirse en una victoria para la humanidad.

Secretariado para la Justicia Social

Roma, 7 febrero 2003

9 Juan Pablo II, Pacem in terris. Una tarea permanente, 1 enero 2003. 